\title{
Prevalence and risk factors for urinary incontinence in pregnant women during late third trimester
}

\author{
Aruna Nigam*, Ayesha Ahmad, Diksha Gaur, Arifa A. Elahi, Swaraj Batra
}

Department of Obstetrics and Gynaecology, Hamdard Institute of Medical Sciences and Research, Jamia Hamdard, New Delhi-110001, India

Received: 26 April 2016

Accepted: 02 June 2016

\section{*Correspondence:}

Dr. Aruna Nigam,

E-mail: prakasharuna@hotmail.com

Copyright: $\odot$ the author(s), publisher and licensee Medip Academy. This is an open-access article distributed under the terms of the Creative Commons Attribution Non-Commercial License, which permits unrestricted non-commercial use, distribution, and reproduction in any medium, provided the original work is properly cited.

\section{ABSTRACT}

Background: Urinary incontinence (UI) is defined as any involuntary urinary leakage by the International continence society (ICS). The objective of this study was to analyze the prevalence and risk factors of urinary incontinence in pregnant women in late third trimester.

Methods: A questionnaire based survey done on 400 pregnant women in third trimester beyond 34 weeks of gestation. A pretested, semi structured questionnaire was used to enquire about demographic and personal information regarding age, parity, education, occupation, type of delivery, weight, height, smoking, constipation and coffee consumption, regular physical activities, family history of UI, history of UI pre-pregnancy and during the previous pregnancy. Detailed history was taken regarding urgency, urge urinary incontinence (UUI), nocturia, bed wetting, dysuria, stress urinary incontinence (SUI) and sensation of incomplete emptying.

Results: Prevalence of urinary incontinence was found to be $75.25 \%$. Majority $(72.7 \%)$ of the women complained of stress urinary continence. History of urinary tract infection was present in $35.75 \%$ of women during pregnancy. $81.25 \%$ complained of increased frequency and $89 \%$ complained of nocturia. Significant association was found between the urinary incontinence and pregnancy $(\mathrm{p}=0)$, multiparity $(\mathrm{p}=.007)$ and smoking $(\mathrm{p}=0)$.

Conclusions: High prevalence of UI among apparently healthy women. Major risk factors were urinary tract infection, sedentary lifestyle, constipation, multiparity and smoking.

Keywords: Incontinence, Pregnancy, Urgency, Nocturia, Dysuria

\section{INTRODUCTION}

Urinary incontinence (UI) is defined as any involuntary urinary leakage by the International continence society (ICS). ${ }^{1}$ The prevalence of UI in women varies from 13 to $35 \%{ }^{2}$ Important factors implicated in causation of UI in reproductive age group females are pregnancy, anatomical defects developing after delivery, changes in hormonal and urethrovesical angle, increased pressure on levator muscles, connective tissue and ligaments. The other risk factors which contribute towards UI include advanced age, multiparity, multiple pregnancy, smoking, alcohol consumption, coffee consumption, raised body mass index, diabetes and constipation.
Factors causing remission of UI have not been well studied but would include reversible causes of incontinence i.e. urinary tract infection, urogenital atrophy, pregnancy, weight changes.

During pregnancy the prevalence of UI has been observed at $23 \%$ in first trimester to $67 \%$ at the end of pregnancy, and from $6 \%$ to $29 \%$ from 6 months up to 1 year post-partum. ${ }^{3,4}$ Observational studies have consistently shown that pregnant women with UI have significantly lower quality of life (QoL) during pregnancy than those without UI, and the QoL worsens as gestational age increases. ${ }^{5}$

Conservative statistics estimate that $10 \%$ of women more than 18 years and $33 \%$ of women more than 40 years are 
plagued by UI. ${ }^{6}$ However, despite being such a common problem, it may not be reported and there may be long delays between onset and when women seek help for it. It has been observed that only $20 \%$ of women with UI seek help. ${ }^{6}$ The main reasons are a lack of knowledge and embarrassment.

This study was planned to estimate the burden of UI in pregnant women and explore associated risk factors. And the objective of this study was to analyse the prevalence of UI in pregnant women in late third trimester. And to analyse the risk factors leading to development of UI in antenatal women.

\section{METHODS}

The present study was a descriptive, cross sectional, questionnaire based survey carried out at Hakeem Abdul Hameed Centenary Hospital associated with Hamdard Institute of Medical Sciences and Research, Jamia Hamdard, New Delhi, India. The study was approved by the Institutional ethical committee. A total of 400 subjects were recruited from the antenatal women attending the outpatient clinics or admitted as in patients.

\section{Inclusion criteria}

All healthy pregnant women in third trimester beyond 34 weeks of gestation, who agreed to be part of the study and given written informed consent, were recruited in the study.

\section{Exclusion criteria}

Women with a high risk pregnancy, women with a period of gestation less than 34 weeks, laboring patients and those who did not agree to comply with the formalities of the consent form and questionnaire.

A pretested, semi structured questionnaire was used to enquire about demographic and personal information regarding age, parity, education, occupation, type of delivery, weight, height, smoking, constipation and coffee consumption, regular physical activities, family history of UI, history of UI pre-pregnancy and during the previous pregnancy. Detailed history was taken regarding urgency, urge urinary incontinence (UUI), nocturia, bed wetting, dysuria, stress urinary incontinence (SUI) and sensation of incomplete emptying. The questionnaire was based on International consultation on incontinence questionnaire (ICIQ) short form. ${ }^{7}$ The data was collected by face to face interview. During the interviews, questions were read, and the appropriate choices marked on the questionnaire according to the answers. Confidentiality of data was emphasized and ensured.

\section{Sample size and data analysis}

The criterion adopted to classify a pregnant woman as incontinent was based on the ICS definition corresponding to any person who had confirmed urinary leakage, regardless of the amount leaked.
As the prevalence of UI among pregnant women varies between $23 \%$ to $67 \%$ in published literature, a conservative estimate of prevalence of $40 \%$ is used, than according to formula. ${ }^{8}$

$\mathrm{N}=\mathrm{Z}^{2} \mathrm{P}(1-\mathrm{P}) / \mathrm{e}^{2}$

The sample size was calculated to be 369 , thirty additional subjects were enrolled as a security measure bringing the sample size to 400 .

Recorded data was entered in Microsoft excel worksheet 2007 and analyzed using SPSS version 20. The assessment of the relation between UI and its risk factors was done using the pearson chi-square test. Statistical significance is set at the $5 \%$ level $(\mathrm{p}<.05)$.

\section{RESULTS}

Table 1: Demographic characteristics.

\begin{tabular}{|c|c|c|}
\hline Age & $\mathbf{N}$ & $\%$ \\
\hline 20 and less & 19 & 4.75 \\
\hline 21 to 25 & 194 & 48.5 \\
\hline 26 to 30 & 162 & 40.5 \\
\hline 31 to 35 & 25 & 6.25 \\
\hline Total & 400 & \\
\hline \multicolumn{3}{|l|}{ Education } \\
\hline Illiterate & 28 & 7 \\
\hline Incomplete Schooling & 93 & 23.25 \\
\hline Class $10^{\text {th }}$ & 109 & 27.25 \\
\hline Class $12^{\text {th }}$ & 55 & 13.75 \\
\hline Graduate & 84 & 21 \\
\hline Post graduate & 31 & 7.75 \\
\hline Total & 400 & \\
\hline \multicolumn{3}{|l|}{ Occupation } \\
\hline Housewife & 384 & 96 \\
\hline Office job & 16 & 4 \\
\hline Strenuous jobs & None & \\
\hline Total & 400 & \\
\hline \multicolumn{3}{|l|}{ Religion } \\
\hline Hindu & 95 & 23.75 \\
\hline Muslim & 32 & 8 \\
\hline Sikh & 1 & 34.4 \\
\hline Total & 400 & \\
\hline \multicolumn{3}{|l|}{ BMI } \\
\hline Less than 18 & 50 & 12.5 \\
\hline 18 to 24.9 & 271 & 67.75 \\
\hline 25 to 29.9 & 56 & 14 \\
\hline 30 and above & 23 & 5.75 \\
\hline Total & 400 & \\
\hline \multicolumn{3}{|l|}{ Booking for ANC } \\
\hline First trimester & 88 & 22 \\
\hline Second trimester & 180 & 45 \\
\hline Third trimester & 124 & 31 \\
\hline Unbooked & 8 & 2 \\
\hline Total & 400 & \\
\hline
\end{tabular}


Table 2: Urinary problems during pregnancy.

\begin{tabular}{|c|c|c|}
\hline $\begin{array}{l}\text { Type of impairment of } \\
\text { QOL }\end{array}$ & n & $\%$ \\
\hline None & 6 & 1.5 \\
\hline Slight & 76 & 19 \\
\hline Moderate & 188 & 47 \\
\hline Severe & 31 & 7.75 \\
\hline Total impairment & 295 & 73.7 \\
\hline \multicolumn{3}{|l|}{ Types of incontinence } \\
\hline Mixed & $66 / 301$ & 21.9 \\
\hline Stress only & $219 / 301$ & 72.7 \\
\hline Urge only & $16 / 301$ & 4 \\
\hline \multicolumn{3}{|l|}{ Hesitancy } \\
\hline Slight & 118 & 29.5 \\
\hline Moderate & 52 & 13 \\
\hline Severe & 40 & 10 \\
\hline \multicolumn{3}{|l|}{ UUI alone } \\
\hline Slight & 5 & 1.25 \\
\hline Moderate & 8 & 2 \\
\hline Severe & 3 & 0.75 \\
\hline \multicolumn{3}{|l|}{ SUI alone } \\
\hline Slight & 99 & 24.7 \\
\hline Moderate & 105 & 26.2 \\
\hline Severe & 15 & 3.75 \\
\hline \multicolumn{3}{|l|}{ Amount of urine leaked } \\
\hline Slight & 25 & 6.25 \\
\hline Moderate & 13 & 3.25 \\
\hline Severe & 9 & 2.25 \\
\hline \multicolumn{3}{|c|}{ Urgency with/without incontinence } \\
\hline Slight & 81 & 4.1 \\
\hline Moderate & 65 & 16.25 \\
\hline Severe & 210 & 52.5 \\
\hline \multicolumn{3}{|c|}{ Frequency ( $>=10$ micturitions a day) } \\
\hline & 325 & 81.25 \\
\hline \multicolumn{3}{|c|}{ Nocturia (>=3 night voids) } \\
\hline & 356 & 89 \\
\hline \multicolumn{3}{|l|}{ Bed wetting } \\
\hline & Nil & Nil \\
\hline \multicolumn{3}{|c|}{ Constipation (<3 bowel movements per week) } \\
\hline & $290(72.5 \%)$ & $110(27.5 \%)$ \\
\hline \multicolumn{3}{|c|}{ Regular exercise (at least 3 times per week) } \\
\hline & $9(2.25 \%)$ & $391(97.75 \%)$ \\
\hline
\end{tabular}

The demographic characteristics of study population are shown in Table 1. Maximum subjects recruited were between 21 to 30 years of age. Majority had completed basic schooling of Class $10^{\text {th }}$ and beyond $(279,69.75 \%)$. None of the women reported performing strenuous jobs or lifting heavy weight; most of them were housewives, and involved in daily household chores. Of the minority subjects who were working, all were employed in office jobs.

$153(38.25 \%)$ subjects were nulliparous, $247(61.75 \%)$ were parous women. 121 out of 247 parous women $(48.98 \%)$ gave positive history of incontinence in previous pregnancy. Constipation in the index pregnancy was reported by 290 women $(72.5 \%)$. It was usually associated with moderate discomfort.

Table 2 describes the urinary problems during pregnancy. 301 women $(75.25 \%)$ reported urinary incontinence. $98 \%$ $(295 / 301)$ of them reported some impairment in quality of life. 143 subjects $(35.75 \%)$ reported with history of UTI at least once during pregnancy.

Table 3: Association between risk factors and urinary incontinence during pregnancy.

\begin{tabular}{|c|c|c|c|}
\hline Variables & Yes & No & P value \\
\hline UI during pregnancy & 301 & 99 & \multirow{2}{*}{$\begin{array}{l}\text { chi square }= \\
230, P=0\end{array}$} \\
\hline UI before pregnancy & 52 & 249 & \\
\hline \multicolumn{4}{|c|}{ Daily tea consumption } \\
\hline$<=1$ cup a day & 239 & 72 & \multirow{2}{*}{$\begin{array}{l}\text { Chi square }= \\
1.91, p=0.16\end{array}$} \\
\hline$>2$ cups a day & 62 & 27 & \\
\hline \multicolumn{3}{|l|}{ Parity } & \multirow{3}{*}{$\begin{array}{l}\text { Chi square }= \\
7.04, p=0.007\end{array}$} \\
\hline Nulliparity & 104 & 49 & \\
\hline $\begin{array}{l}\text { Multiparity } \\
\text { (>=2 deliveries) }\end{array}$ & 197 & 50 & \\
\hline $\begin{array}{l}\text { Women exposed to } \\
\text { smoking }\end{array}$ & 156 & 91 & \multirow{4}{*}{$\begin{array}{l}\text { Chi square }= \\
50.69, p=0\end{array}$} \\
\hline Active smoker & 5 & 7 & \\
\hline Passive smoker & 141 & 94 & \\
\hline $\begin{array}{l}\text { Women not exposed } \\
\text { to smoking }\end{array}$ & 145 & 8 & \\
\hline
\end{tabular}

Table 3 illustrates the association between different risk factors and urinary incontinence during pregnancy. Significant association was found between the urinary incontinence and pregnancy, multiparity and smoking (active or passive).

\section{DISCUSSION}

UI is classified as urgency urinary incontinence (UUI), stress urinary incontinence (SUI) and mixed urinary incontinence (MUI). UUI is involuntary urinary leakage accompanied with or preceded by a sudden compelling desire to pass urine, which is tough to defer. SUI is defined as an involuntary leakage of urine during exertion, or during episodes of coughing or sneezing. MUI is a combination of SUI and UUI. Overall, SUI is the most prevalent type of UI, followed by MUI and UUI. $^{9}$

Prevalence studies on UI in pregnancy show a wide variation in their estimation of the problem, depending upon the study design, stages of pregnancy and how UI is defined. $^{10}$ Majority of studies are available from developed countries, with scanty data from Southeast Asia. The prevalence of UI in our population was found to be $75.25 \%$ (301/400). The prevalence of UI observed in the present study is higher because of higher rates of concomitant UTI in our population. It has also been reported that estimate of prevalence is higher when more 
inclusive definitions are used such as 'any urine losses' as in our study and lower when the patient presenting with the complaint of urinary leakage are taken. ${ }^{11}$ Parity was found to be significantly related to UI. Inadequate antenatal care and poor patient compliance may also be reasons for such a high prevalence of UI in pregnancy in our study as majority of the patients had booked after first trimester was over and some had been booked in the third trimester. Wesnes et al found that the prevalence of UI increased from $26 \%$ before pregnancy to $58 \%$ at 30 weeks of gestation. $67.9 \%$ of nulliparas and $79.7 \%$ of parous women complained of UI in our study. ${ }^{3}$ The prevalence of UI ranged from 15 to $48 \%$ in nulliparous women by Wesnes et al. ${ }^{3}$ A higher prevalence of 35 to $67 \%$ was seen in parous women.

Frequency is generally reported as being the most common urinary symptom in pregnancy. Pregnancy has significant impact on physiology of lower urinary tract irrespective of parity. We found a high prevalence of frequency $(81.25 \%)$ in the study subjects. The reported prevalence of urinary frequency in various studies ranged from $12.9 \%$ in third trimester, $40 \%$ by Cutner et al to $70.3 \%$ by Scarpa et al. ${ }^{12-14}$

The prevalence of urgency was also high in our study (89\%) as compared to other studies i.e. $22.9 \%$ by Chaliha $\mathrm{C}$ et al, $27.1 \%$ by Wesnes et al $62 \%$ by Adaji et al. ${ }^{3,13,15}$

High prevalence rate $(89 \%)$ of nocturia in the present study is comparable to other studies. Adaji et al similarly reported a prevalence of nocturia as $94.6 \%$ by the third trimester. ${ }^{12}$ However Cutner et al found a prevalence rate of $23 \%$ for nocturia by end of first trimester. ${ }^{13}$ We think that prevalence of nocturia may vary with definition and also with gestational age.

In the present study, amongst all patients with UI, maximum had SUI. Other studies have also found that SUI has the highest prevalence amongst all types of UI in pregnancy. ${ }^{16}$ We found SUI in $59.25 \%$ subjects, UUI in $37.5 \%$ and MUI in $1.75 \%$. Literature quotes SUI during pregnancy with prevalence ranging from $18.6 \%$ to $75 \%$ comparable to our study. ${ }^{17-20}$

Although higher age group, higher BMI, smoking, constipation and lack of exercise were found to be important high risk factors for UI in many studies. ${ }^{21,22}$ however, we found that even in young patients and those with normal BMI the prevalence of UI is high. This highlights that it is not elderly gravidas and women with high BMI who are at risk but all women are potential candidates for UI in pregnancy. Lack of exercise was found very commonly in all groups of women in the present study. Exposure to smoking, either active or passive was found to be significantly associated with UI in the present study.

The exact causes of pregnancy related SUI remains unclear. Pelvic floor muscle weakness leading to increased bladder neck and urethral mobility is attributed to cause urethral sphincter incompetence. Pelvic floor muscle exercises have been shown to be an effective treatment for prevention as well as treatment of SUI during pregnancy and post-partum period. They are a safe and simple treatment modality and can be done irrespective of time and place. We found a very low prevalence of regular exercising during pregnancy. Importantly, none of the study subjects had been introduced to pelvic floor exercises during pregnancy or post-partum period, neither in the current pregnancy nor in a previous one for parous women. For a condition as prevalent as UI, often debilitating, we need to increase the awareness of urinary incontinence and pelvic floor muscle exercises. Women should be offered pelvic floor muscle exercises in an effort to improve the QOL in pregnancy.

UI remains a disabling condition and carries a significant impact on QOL. In order to provide quality care to pregnant women, we need to be aware of the prevalence of UI in pregnancy. All patients should have careful assessment of the condition as it remains under reported.

Limitations of the study were the prevalence rate of urinary complaints varies with the stage of pregnancy, and our study is restricted to third trimester, the data can't be extrapolated to the whole duration of pregnancy.

We did not segregate women with appropriate antenatal care and women with either inadequate care or noncompliance with advice. Therefore we find a much higher prevalence of UTI, some of the high prevalence of UI found in the present study may be attributed to this.

\section{CONCLUSION}

The present study was conducted to estimate the prevalence of UI during pregnancy and determine risk factors for UI. We found a high prevalence of UI among apparently healthy women. Major risk factors were urinary tract infection, sedentary lifestyle and constipation.

With this data, the authors aim to emphasize the importance of UI and associated risk factors so that the complaints are not taken lightly and adequate professional assistance be provided to pregnant women with UI in order to provide quality care.

Funding: No funding sources Conflict of interest: None declared

Ethical approval: The study was approved by the Institutional Ethics Committee

\section{REFERENCES}

1. Abrams P, Cardozo L, Fall M, Griffiths D, Rosier P, Ulmsten U, et al. The standardisation of terminology of lower urinary tract function: report from the 
standardisation sub-committee of the International continence society. Neurourol Urodyn. 2002;21:167-78.

2. Irwin DE, Milsom I, Hunskaar S, Reilly K, Kopp Z, Herschorn S, et al. Population-based survey of urinary incontinence, overactive bladder, and other lower urinary tract symptoms in five countries: results of the EPIC study. Eur Urol. 2006;50:1306-14.

3. Wesnes SL, Rortveit G, Bø K, Hunskaar S. Urinary incontinence during pregnancy. Obstet Gynecol. 2007;109:922-8.

4. Thompson J, Roberts CL, Currie M, Ellwood DAD. Prevalence and persistence of health problems after childbirth: associations with parity and method of birth. Birth. 2002;29:83-94

5. van de Pol GG, Van Brummen HJ, Bruinse HW, Heintz AP, van der Vaart $\mathrm{CH}$. Is there an association between depressive and urinary symptoms during and after pregnancy? Int Urogynecol J Pelvic Floor Dysfunct. 2007;18:1409-15.

6. Slack M. What's not talked about in women's health. The RCOG consumers' forum public lecture on incontinence and prolapse; 2011. https://stratog.rcog.org.uk/tutorial/incontinence-andprolapse-what-women-do-not-talk-about. Accessed 18 November 2015.

7. Avery K, Donovan J, Abrams P. Validation of a new questionnaire for incontinence: the International consultation on incontinence questionnaire (ICI-Q). Neurourology and Urodynamics. 2001;20:510-2.

8. Naing L, Winn T, Rusli BN. Practical issues in calculating the sample size for prevalence studies. Archieves of orofacial sciences. 2006;1:9-14.

9. Haylen BT, de Ridder D, Freeman RM, Swift SE, Berghmans B, Lee $\mathrm{J}$, et al. An International urogynecological association (IUGA)/International continence society (ICS) joint report on the terminology for female pelvic floor dysfunction. Int Urogynecol J. 2010;21:5-26.

10. Schytt E, Lindmark G, Waldenstrom U. Symptoms of stress incontinence 1 year after childbirth: prevalence and predictors in a national Swedish sample. Acta Obstet Gynecol Scand. 2004;83:928-36.
11. Mac Lennan AH, Taylor AW, Wilson DH, Wilson D. The prevalence of pelvic floor disorders and their relationship to gender, age, parity and mode of delivery. BJOG. 2000;107:1460-70.

12. Adaji SE, Shittu OS, Bature SB, Nasir S, Olatunji O. Bothersome lower urinary symptoms during pregnancy: a preliminary study using the International consultation on incontinence questionnaire. Afr Health Sci. 2011;11(1):46-52.

13. Cutner A, Cardozo LD, Benness CJ. Assessment of urinary symptoms in early pregnancy. Br J Obstet Gynaecol. 1991;98:1283-6.

14. Scarpa KP, Hermann V, Palma PC, Ricetto CL, Morais S. Prevalence of urinary symptoms in the third trimester of pregnancy. Revista da Associacao Medica Brasileira. 2006;3:153-6.

15. Chaliha C, Stanton S. Urological problems in pregnancy. BJU Int. 2001;89:469-76.

16. Sangsawang B, Sangsawang N. Stress urinary incontinence in pregnant women: a review of prevalence, pathophysiology and treatment. Int Urogynecol J. 2013;24:901-12.

17. Mason L, Glenn S, Walton I, Appletion C. The prevalence of stress incontinence during pregnancy and following delivery. Midwifery. 1999;15:120-8.

18. Diez-Itza I, Ibañez L, Arrue M, Paredes J, Murgiondo A, Sarasqueta C. Influence of maternal weight on the new onset of stress urinary incontinence in pregnant women. Int Urogynecol J Pelvic Floor Dysfunct. 2009;20:1259-63.

19. Whitford HM, Alder B, Jones M. A cross-sectional study of knowledge and practice of pelvic floor exercises during pregnancy and associated symptoms of stress urinary incontinence in North-East Scotland. Midwifery. 2007;23:204-17.

20. Huebner M, Antolic A, Tunn R. The impact of pregnancy and vaginal delivery on urinary incontinence. Int J Gynecol Obstet. 2010;110:249-51.

21. Kocaoz S, Talas MS, Atabekoglu CS. Urinary incontinence in pregnant women and their quality of life. J Clin Nurs. 2010;19:3314-23.

22. Sangsawang B. Risk factors for the development of stress urinary incontinence during pregnancy in primigravidae: a review of the literature. Eur J Obstet Gynecol Reprod Biol. 2014;178:27-34.

Cite this article as: Nigam A, Ahmad A, Gaur D, Elahi AA, Batra S. Prevalence and risk factors for urinary incontinence in pregnant women during late third trimester. Int J Reprod Contracept Obstet Gynecol 2016;5:2187-91. 